March - 2007

\title{
Integration of the High-tech and Low-tech in Distance Teacher Training in China: An insight from the Case of Jiangsu Radio and Television University
}

\author{
Zhang Xiangyang \\ Jiangsu Radio and Television University, Peoples' Republic of China \\ Hung Shu-chiu \\ National Central University, Taiwan
}

\begin{abstract}
This paper reports the results of a pilot in-service teacher training program undertaken in China from 2001 to 2004. Upon completion, the in-service teachers were awarded a Bachelor of Arts degree (non-honor) specializing in English Language Education. Many interesting findings resulted from this pilot program. By integrating low- and high-technology in the distance inservice teacher training programs, both the trainers (the university lecturers) and the student teachers (in-service school teachers) were able to transform their pedagogical skills. The student teachers learned to become independent learners. The university lecturers learned to adjust their teaching styles to be more learner-centred. Both the lecturers and the student teachers adopted task-based approaches to learning and teaching. Finally, the student teachers were given the means to upgrade their qualifications and teaching skills. Based on these findings, the authors offer suggestions for the future development of student teacher training in China using distance modalities.
\end{abstract}

Keywords: high-tech and low-tech; distance education; student teacher training; pilot program

\section{Introduction}

In recent years, distance education received more attention than ever before in China. In particular, the application of hi-technology into language education has been widely discussed and proactively adopted among universities. Following this trend, China's educational authorities and administrators are now aware of the need to inject distance teacher training program with new pedagogical materials, methodologies, and technologies. These distance programs are needed for in-service school teachers to upgrade their knowledge, earn qualifications, and improve their approaches to teaching (Wei, 1999; Yu, 1999; Zhang, Niu, \& Jiang, 2002).

In 2001, China's Central Radio and Television University (CRTVU) initiated a nationwide open and distance teacher training program, which was accredited by China's Ministry of Education. Owing to its large network and readily accessible educational system, CRTVU's distance teacher 
training program was well positioned to serve school teachers across a much wider geographical area.

Jiangsu Radio and Television University (JRTVU) is a distance education institution located in Jiangsu Province in China. From 2001 - 2004, JRTVU was involved in a pilot three-year BA degree (non-honor) program designed to upgrade the skills and qualifications of in-service school teachers who teach English, by providing them with new pedagogical materials, methodologies, and technologies at a distance. This paper reports on the open entry pilot BA program (20012004), which integrated hi-tech and low-technologies in open and distance learning and teaching.

Bates (1995) cites four main reasons for employing distance education (DE) in teaching:

1. DE helps widening access to formal and non-formal learning opportunities

2. DE is cost-effective

3. DE flexibility is excellent in helping re-orient teachers in times of educational change

4. DE can help expand the supply of qualified teachers

According to a national survey conducted in 1997, only 51 percent of China's senior middle school teachers had a four-year college education, a number far from the 70 percent target stipulated by China's Central Government for the year 2000 (State Council 1994). Consequently, CRTVU was directed by China's Ministry of Education to commence distance teacher training to upgrade China's school teachers using an open door policy, meaning this program was open to all in-service teachers.

As of 1999, in Jiangsu Province, 80.56 percent of senior middle school teachers had a Bachelor's degree, a number that clearly exceeds the minimum national requirements. However, in terms of junior middle school teachers, only 13.39 percent held a Bachelor's degree (Jiangsu Educational Council, 2000), a number that falls far short of the minimum national requirement of 70 percent. As such, Jiangsu's educational authorities are aiming high for all secondary school levels. This is good news not only for China, but for the teachers as well, as there existed, in general, a strong desire among school teachers to upgrade their qualifications.

Owing to its established network in Jiangsu Province, a network that consists of affiliated teaching and learning centers, the Jiangsu Radio and Television University, was also well situated to take part in this program. As such, JSRTVU has played a key role in the pilot BA teacher training program, delivered at a distance.

\section{Aims of the Program}

This program aimed to upgrade China's junior and senior school teachers' qualification, develop their pedagogic and linguistic competencies, teaching methods and strategies, learning strategies, as well as their language knowledge and ability (listening, speaking, reading and writing in English).

Student teachers enrolled in this DE program are granted a BA degree upon satisfactory completion of the eight-year program. Their academic credentials have been validated by the China's State Ministry of Education, and awarded through the CRTVU. The program is a creditbased program, comprising of 11 compulsory courses, including three orientation courses. To earn their BA, these student teachers are expected to: 
- Build upon their basic knowledge of the English language

- Acquire the motivation and skills for lifelong learning

- Gain a better understanding of current developments in Education of language education

- Become equipped with new teaching materials, methods, and course designs

- Develop their capability for designing syllabi

- Carry out action research in their classrooms

- Use and incorporate modern educational technologies to their teaching

\section{The Organizational Structure}

CRTVU acted as the headquarters for the distance training education. For this program, CRTVU cooperated with the British Council. Beijing Foreign Studies University (BFSU) was the primary program provider and evaluator. JSTVU, on the other hand, was a provincial partner of CRTVU, and involved in course design, tutoring, administration, course monitoring, and assessment. JSTVU is comprised of 14 local learning centers located in cities and municipalities scattered throughout Jiangsu Province. Each local learning centre employs a manager, tutors, assessors, monitors, and learner caretakers. In sum, the learning centers' job is to relay the courses and instructions to student teachers, who are often working in small towns and in outlying rural areas.

CRTVU, BFSU, and JSTVU use the Internet as its primary means of communication. ATM networks have been established with the LANs-based learning centers throughout the Province. The organization structure of this partnership is outlined in Figure 1.

Figure 1. The organizational structure of the three partner institutions






\section{Course modules}

The pilot BA program was designed, developed, and produced by a course team jointly drawn from the BFSU, the British Council, and CRTVU. The program is comprised of two modules. The first is called English Language Communication and is comprised of eight courses (144 hours study for each course). The first module aims to improve the in-service teachers' proficiency in English. The second module, called Professional Training, is comprised of three courses (288 hours for each course). The purpose of the second module is to provide the student teachers hands-on professional development, as well as much needed time (three months) to practice and become proficient with the English language teaching methodologies learned.

The multi-media course materials were thematically structured and task-based, and comprised of print-based course textbooks, audio cassettes, and videos.

\section{High-tech and Low-tech Integration in Course delivery}

Reiser and Gagne (1983) advise that the selection of the teaching and learning media should be executed in line with the learning context. Wichit (1997) summarizes five factors that must be taken into consideration when using technology for course delivery.

1. Availability of adequately developed technology

2. Accessibility of media for both the teaching institution and the learners

3. Acceptability to both teachers and students

4. Validity or appropriateness of the media in achieving the objectives of the learning materials

\section{Cost-effectiveness}

The application of high technology was the priority of the pilot BA program. Thus, designers of the program sought from the outset to integrate hi-technology (computer-based) and lowtechnology (traditional) as its instructional technologies.

\section{Assessment and Evaluation}

Formative and summative assessing activities were adopted to evaluate the student teachers' progress through the program. The formative assessment accounted for 20 percent, while the summative assessment accounted for 80 percent of the total for the assessment. If the student teachers had no formative assessment on record, or if they had failed it, these student teachers automatically lost the right to sit the end-of-term examination. The student teachers, therefore, could only obtain credit when they passed the two forms of assessments (minimum pass of 60 percent). 


\section{Implementation of the Program in JRTVU and Local Centers}

\section{The trainers (university lecturers)}

The cohort of university lecturers - herein called tutors or trainers for convenience sake consisted of part-time instructors drawn from conventional universities located within the vicinity of each JRTVU learning centre (six local centers at first, and 14 local centers at the end) and full time instructors drawn from JRTVU. Most university instructors also worked as tutors at the local learning centers, while a handful worked as consultants to the JRTVU managerial team.

In this pilot program, the tutors' task was to proactively support and track the student teachers' learning process and progress. As such, the tutors' role involved acting as a:

- Needs analyst

- Motivator

- Resource provider

- Organizer and controller of the in-service teachers' behavior in tutorials

- Demonstrator of the language teaching

- Monitor of in-service teachers learning

- Assessor of the in-service teachers’ performance

- Counselor and friend to in-service teachers

\section{Student teachers}

Two-hundred, twenty $(n=220)$ student teachers enrolled in JRTVU during the first year the program was offered. A similar number of student teachers joined in the second year, reaching the total number of 992 program student enrollees by 2004.

The student teachers came from different (mostly rural) areas of Jiangsu Province. Most had taught English for at least three years to 10 years; only a few reported having taught 20 years or more. The age of the student teachers ranged from 21 to 50 years old. Most were female and most shared the following characteristics:

- Most were middle aged

- Lacked of confidence in their prior education

- Shouldered heavy work loads at home and at their schools

- Displayed poor competencies in using English and technology

- Experienced frustration and panic learning at a distance

- Embraced spoon-fed traditional teaching and learning strategies 
- Showed strong motivation for upgraded qualification

Figure 2. Model of implementation of integratration with High-technology and Low-technology (

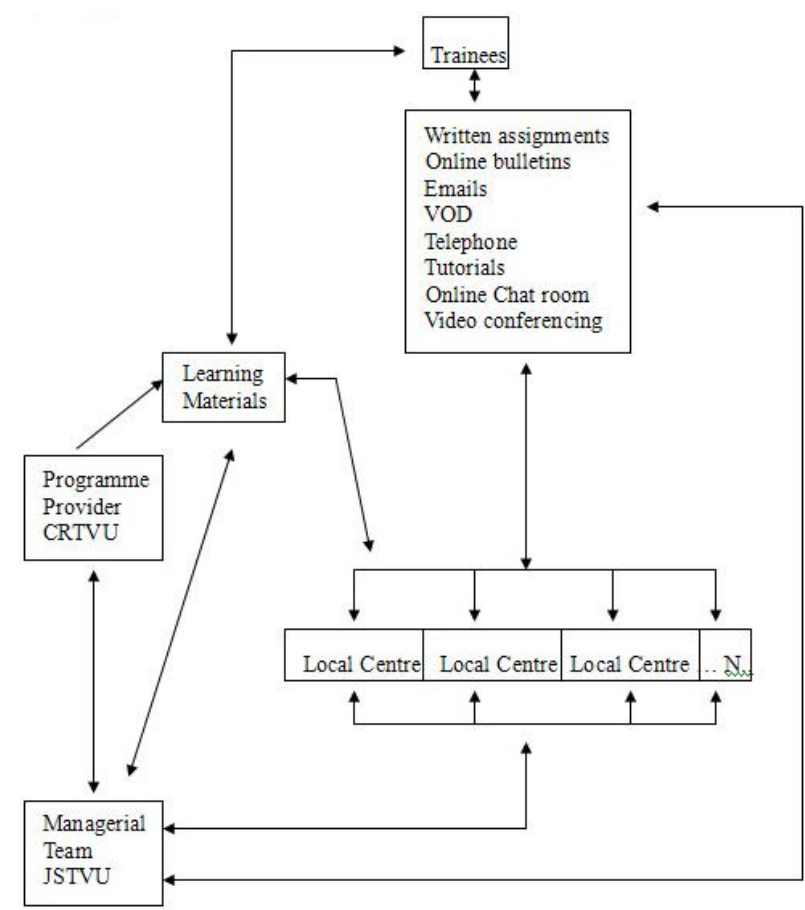

Adapted from (Tong, Wei and $\mathrm{Xu}, 1999$ )

All course curricula were posted to specifically designed Website and an online platform housed at JRTVU. This online platform was designed to:

- Provide student teachers a means to familiarize themselves with the course via its syllabus, desired learning outcomes, etc.

- Deliver news and notices

- Deliver teaching/ tutoring components of the course online

- Provide a forum for online discussions

- Allow the student teachers a means to upload their assignments, perform online tests, etc.

- Track the student teachers' activities and their overall learning processes

While the student teachers:

- Submitted their assignments and received feedback from the tutors

- Browsed the online course materials and performed Web-based searches 
- Participated in the online discussions and tutorials

- Completed online tests and assessments

\section{Tutorials}

Implementing a skill-based program within an open and distance learning (ODL) environment, particularly in terms of pedagogical skills development in the form of writing and speaking, was a great challenge for the JRTVU managerial team and the pool of tutors. In the field of language teaching, there has been a move away from passive approaches to language learning (i.e., the grammar-translation approach) towards a more active and participatory approach (i.e., communicative, oral language teaching).

To compensate for the lack of 'oral communication' inherent within older distance learning settings, synchronous online and face-to-face tutorials were designed and delivered to the student teachers. This approach to teacher training in rural areas, however, is unlike those practiced in other developing countries such as Brazil (Bof, 2002), Botswana (Bose, 2003), and Rwanda, (Mukamusoni, 2006), authors who have reported using a blend of face-to-face tutorials in support of its distance education offerings, typically held during teachers' summer vacations.

\section{Monitoring and Quality Assurance}

Online learning activities, oral and written assignments, face-to-face tutorials held at the local centers, and final assessments were used to track, monitor, and evaluate the student teachers' performance and progress through the course. The course was 'paced' using pre-set deadlines for written assignments deliverable online or via post. This meant that the student teachers had to learn how to use their effectively and efficiently. As such, these monitoring activities helped the student teachers to arrange their schedules, pace their efforts, and use their limited time accordingly.

To ensure that the student teachers were receiving appropriate, high-quality feedback from their tutors, marked and graded student teacher assignments were randomly selected and assessed by an expert in English teaching. Not only did this ensure the quality of teaching, it helped JRTVU to assist and target tutors who themselves may need upgrading and training. Regular meetings each semester provide tutors with face-to-face feedback on their performance. On site school visits had been discussed, but were later abandoned due to funding.

Three questionnaires were designed, distributed, and analyzed. Questionnaire 1 focused on the needs of the student teachers, their educational background, their English learning and teaching information, as well as their expectations for the program. Questionnaire 2 aimed to track and assess the student teachers' performance one year after the pilot program. Questionnaire 3 was an overall investigation of the student teachers, specifically their reflections on the three years' with the program, and evaluation of the program. Focus groups and local visits were also arranged for both the student teachers and their tutors', to allow reflection on their involvement with the program.

\section{Results and Analysis of the Pilot Program}

Qualitative and quantitative data collected and complied on the 2001 cohort (this cohort had completed the full three year cycle) shows that the pilot program was considered to be quite successful. The drop out rate was very low, at less than 3 percent. This figure is much lower than 
reported in other distance programs offered by conventional universities (Zhang, et al. 2002). The main explanation for this low dropout rate is, however, likely due to the student teachers motivation. Most student teachers indicated they would continue with their learning because if they failed to earn a Bachelor's degree, they would lose their teaching post.

Interesting findings have been unexpectedly observed as well. The integration of low-tech and high-tech appeared to work together in a complementary fashion. Tutors and student teachers alike reported that they had greatly advanced their language learning and teaching skills, primarily due to the integration of high-technology Web-base teaching modes with that of traditional low teach distance teaching methods.

\section{Evaluation from the student teachers}

In sum, the data collected indicates that the vast majority was satisfied with the pilot program. Here is the brief statistical summary of feedback gathered from student teachers:

Efficiency of learning by distance:

- $69.4 \%$ of the student teachers indicated that they spent at least one hour each day engaged in independent learning activities

- 83.9\% reporting having followed the learning sequences as stipulated by the learning materials

- $71.8 \%$ reported that they had made substantial progress in their language and communication skills

- $70.6 \%$ of the student teachers indicated that it was feasible to learn at a distance, because they learned to manage their own learning

- $85.5 \%$ reported being satisfied with their progress

- 52\% reported having become computer literate

- $77.3 \%$ reported that they felt that access to computers and the Internet had helped in their distance learning

- $77.4 \%$ reported that they had browsed the website every week

- 87.6 reported that they used the computers at their learning centers to log on the course website

- 74.4 reported that the course helped improve their classroom teaching

Appropriateness of learning materials and method of course delivery:

- $86.4 \%$ indicated that they felt the learning materials were appropriate for distance learning

- $94.1 \%$ felt the learning materials were relevant to their profession

- $74.3 \%$ thought the task-based course books helped them to upgrade their language 
teaching skills and learning autonomy

- 96.9\% indicated that high technology is more efficient when integrated with traditional DE technology

- $60.4 \%$ reported that the course website was easy to access and use

- $72.7 \%$ reported the information published on the course website as satisfactory

- $45.0 \%$ felt they could easily interact with their peers online

Quality of learner support:

- $72.3 \%$ of student teachers felt it was feasible to learn at a distance combined with faceto-face tutorials

- $45.2 \%$ reported that 'learner support' available to them was excellent; while 37.1\% reported it to be satisfactory

- $86.4 \%$ reported that the tutors’ written feedback was helpful

- $77.9 \%$ felt that the face-to-face tutorials were demonstrative of tutors' oral, communicative language teaching skills

- 98.9\% felt the staff at the local learning centers were quite friendly

- $87.6 \%$ reported email as effective for communication

- $66.4 \%$ indicated that their tutors were easy to contact

- $73.7 \%$ reported that the course website provided them with timely feedback

Personal and professional achievements received:

- $30.6 \%$ reported having received a professional promotion

• 6.7\% having received local 'Teaching Excellence Awards'

After the questionnaires, informal interviews were conducted. The outstanding response reported was that the student teachers had 'learned how to learn' by themselves. They indicated that their overall performance in their middle schools - especially in oral language skills - had improved tremendously, and had positively influenced their colleagues and students. Most student teachers, however, worried whether they would feel out-of-place, like a "Crane among the Chickens" or whether they would revert to their timeworn, traditional teacher-centered, examination-oriented teaching and learning styles.

\section{Evaluation from the tutors}

Generally, the tutor feedback was also positive. Feedback was gathered using focus groups, and via personal and informal face-to-face interviews. Tutors from the conventional universities reported they were generally satisfied with the learning materials, approaches used in course implementation and the monitoring and assessment system (which, they reported, helped the 
student teachers to better manage their time). On a down note, the tutors reported that preparations for the tutorials were very time consuming and very difficult. Course activities had to be designed and teaching materials collected before the face-to-face tutorials, typically at the last minute, to match the needs of the cohort. Because the students had read chapters before they entered the classroom, this left the tutors little need to lecture on topics covered in the text.

Some tutors also reported that they were reluctant to change and transform their teaching strategies. Just as the student teachers had to learn to become 'independent learners,' so too did the tutors have to learn to become more 'student-centered' by asking and posing questions, offering more authentic tasks, etc.

\section{Problems Experienced}

\section{High-cost, low-efficiency for a provincial partner}

Based on the data collected, the authors determined that the program is high cost/ low efficiency. This finding is based on the number of student teachers enrolled, tutors' workload, and need to equip the learning centers with computers and Internet connectivity. Indeed, each learning centre had to be equipped with computing centers to support the student teachers. Access to Internetconnected computers was also a requirement for enrolment. Theoretically, each student teacher should own their own computer, but this clearly was not the case. In fact, even in more developed Asian countries such as Korea, which enjoys high connectivity (Jung, 2001), ownership of personal computers among student teachers is relatively low. This fact alone contradicts the theory of cost-effectiveness of ODL in terms of increasing access at low cost. This finding also mirrors that found in conventional universities, as reported by Zhang and colleagues (2002).

\section{Learner readiness}

Teachers' beliefs and practice are typically hard to change. One reason is because teachers are conditioned by their prior learning experiences, typically learned in schools and higher educational institutions where face-to-face classroom teaching dominates. Using high technologies may pave the way to independent learning and autonomous learning; however, in practice, tutors indicated that they expend much more energy and put much more effort into tutoring online in 'learner centered' contexts - the pedagogic strategies needed in distance learning settings! Meanwhile, many of students enrolled in the pilot program reported that they have work colleagues studying at other higher educational institutions using traditional approaches of learning and teaching. As such, we felt 'brainwashing' to be a necessity, especially at the beginning phase of a distance-learning course of study. Continuous efforts have been made in helping the student teachers' gain more proficiency using ICT technologies (this is an optional course).

\section{Quality vs. quantity}

We found that open entry does not mean open to all those who are interested in the program. For instance, we have found some learning centers had accepted non-teachers into this program, which resulted in the students feeling frustrated and upset, because they were simply not prepared or academically equipped to participate effectively. The reason clearly lies in the 'quantity' requirement - so many students must be enrolled, which means quantity has watered-down the quality. This accidental finding gives rise to one possible solution: universities should consider offering a new pre-service teacher-training program or some other type of induction course for those who wish to seek teaching as a career option. 


\section{Forms of assessment}

The assessment and evaluation adopted in the pilot program are still rather traditional, that is, paper-based and memory-based. The current practice in the final exam is not well suited for working adults or for online learning generally. Consequently, most student teachers had made special preparations for their final exam (rote memorization), which keeps them from becoming life-long learners and may hinder their later professional development in engaging in authentic learning. The educational authorities still adhere to this kind of assessment, however, although the experts from the British Council have suggested another route.

In summary, through the program implementation, the authors conclude that:

- These traditional school teachers (a.k.a., student teachers in this paper) have become independent learners as they progress through their studies

- The university teachers (tutors) have learned how to change their classroom teaching style to be more learner-centered and less teacher-centered

- The oral, communicative task-based approach was quite good, and unexpectedly adopted and incorporated into the student teachers' learning and teaching process

- The student teachers not only upgraded their qualifications, but they also upgraded their teaching methodologies use

\section{Some Insights from the Pilot Program in Jiangsu}

The distance teaching system used at the JRTVU used a blended learning and teaching system. By design, in responding to the needs of the student teachers, courses were delivered via using a blend high- and low-technology delivery and teaching methods. The courses have been found to be instrumental in challenging long held beliefs about where, when, and how teaching and learning should take place. What is critical is not where the learners are located, but whether they can interact with their tutors or the course materials. With the completion of the pilot program at JRTVU, the following characteristics can be reported:

\section{The merging of the high- and low-technology delivery systems}

In an ODL institution like JRTVU, the target group of students is typically heterogeneous in terms of age, experience, qualification, and learning styles. As such, the pilot program was designed for individualized learning, mapping of pathways to learning, and aimed to incorporate and facilitate different learning styles (Gagne, 1985, 1992). Two-way delivery systems were merged and used by one university, specifically offering a face-to-face mode of delivery complemented with multimedia technologies and distance modes of delivery using ICT on a real and a virtual campus. This blended mode of course delivery was found to be very interactive, accessible to all student teachers anywhere, anytime, 24/7. As a result, this program allowed for tremendous access previously not attainable.

\section{Collaboration with conventional universities}

China' Radio and Television University's (RTVUs) hold much lower academic rankings compared to long-established, conventional universities in terms of status, reputation, teaching, students, research, and facilities. RTVU's however, have the reach that traditional universities 
cannot have. Collaboration with the conventional universities should therefore be a priority in providing quality distance education throughout China. JRTVU joined the pilot program partly because it was a joint program with BFSU, which has a good reputation in foreign language teaching. The role of accreditation cannot be over-emphasized and it must be backed-up by the reputation of the organization (Walandouw \& Penrose, 1994). This is especially true in the Chinese cultural context. In practice, however, care must be taken to ensure that quality standards are not compromised and that certificate credibility is maintained.

\section{Quality learning materials for distance learning}

Compared with ODL systems in China, the print course books are specifically designed and prepared for distance learners by dividing learning materials into smaller portions for learners, especially those who cannot afford the luxury of taking off an afternoon from work to study, or even an evening to study at home. In-service teachers in particular, have heavy workloads, teaching 30 hours or more per week, in addition to looking after their families. And while online delivery of the learning materials is very tempting for cost and access conscious administrators, care must always be taken to ensure that the course demands will not negatively impact busy learners.

For example, suppose student teachers are sitting down at their desktop computer screens, reading the relevant course chapters page-by-page, for one hour or more without interruption? Or download and print them? Do they have access to a printer? If so, is the printing affordable? Portable, wireless laptop computers might be one solution. But this option currently does not exist in most parts of China.

\section{Appropriate forms of tutorials}

The Chinese culture of education is based on a tradition of teacher-centered, teacher authority oriented learning styles. Throwing teacher-dependant students (even though they are teachers themselves) into learner-centered 'learning pools' could make them feel like they are drowning, make them lose their sense of direction, frustrate them, and result in loss of confidence.

As such, the JRTVU's practice, the forms of the tutorials, have been selected for specific learning purposes, modes, and contexts. Local learning centers are available to provide face-to-face tutorials, which serve the purpose of training students to 'learn how to learn' in their new ODL context. Whether you agree or not, "face-to-face interaction (where) it is the most appropriate technology” (Moore, 2006, p.132). Low- and high-technology-based tutorials have been used alone or together in support of student learning. The tradition of 'cramming knowledge' gives way to useful knowledge that enables learners to lead a self-directed, informed, and hopefully virtuous life. The contemporary DL programs' approach used by JRTVU now leads student teachers, step-by-step, towards communicative language teaching skills for nearly three years. All tutorial demonstrations conform to the new requirement as articulated by the New National English Teaching Curriculum for Middle Schools (MOE, 2001), which advocates the communicative language teaching approaches.

\section{Conclusion}

In this report, we have dwelt on the background of a pilot student teacher training program. Explored was the design and implementation program through JRTVU and its local centers. The tutors and the student teachers all reported experiencing dramatic changes in their learning and teaching styles as a result. 
Based on current practice at JRTVU, we discovered that technology does not teach - it only provides the tool that enables the delivery of teaching at a distance. This technology shifts the responsibility of learning away from that of the teacher towards that of the individual learner. Still, technology itself and of itself does not teach - only humans can teach and learn how to learn. The challenge for the educational community, therefore, will be to create viable pedagogies take into account - but are not driven by - the particular technology chosen for use (Freeman \& Johnson, 1998).

Through its pilot teacher-training program at a distance, JSTVU has found a suitable model for academic and administrative management in the future ODL contexts. Currently, the blending and integration of high- with low-technologies is the best option to meet learners' needs in China today.

\section{References}

Bof, A. M. (2004) Distance Learning for Teacher Training in Brazil. International Review of Research in Open and Distance Learning, 5(1). Retrieved November 5, 2006 from: http://www.irrodl.org/index.php/irrodl/article/view/172

Bose, K. (2003). An E-Learning Experience: A written analysis based on my experience with primary school teachers in an e-Learning pilot project. International Review of Research in Open and Distance Learning, 4(2). Retrieved November 5, 2006 from: http://www.irrodl.org/index.php/irrodl/article/view/151

Freeman, D., \& Johnson, K. (1998). Reconceptualising the Knowledge-base of Language Teacher Education. TESOL Quarterly, 32(3), 397-417.

Gagne, E. D. (1985). The Conditions of Learning. 4th Ed. New York: Holt, Rinehart and Winston.

Gagne, E. D. (1992). Principles of Instructional Designs. 4th Ed. New York: Holt, Rinehart and Winston.

Jiangsu Educational Council (2000). Statistics of Jiangsu Education 1999.

Jung, I. (2001). Issues and Challenges of Providing Online In-service Teacher Training: Korea's Experience. International Review of Research in Open and Distance Learning, 2(1). Retrieved November 5, 2006 from: http://www.irrodl.org/index.php/irrodl/article/view/30

Ministry of Education (2001). National English Curriculum Standard. Beijing: People’s Education Press.

Moore, M. (2005). Blended learning. American Journal of Distance Education, 19(3) 129-132.

Mukamusoni, D. (2006). Distance Learning Programme of Teachers' at Kigali Institute of Education: An expository Study. International Review of Research in Open and Distance Learning, 7(2). Retrieved November 5, 2006 from: http://www.irrodl.org/index.php/irrodl/article/view/301

Reiser, R. A., \& Gagne, R. M. (1983). Selecting Media for Instruction. Eaglewood Cliffs, NJ.: Educational Technology Publications. 
State Council (1994). The Outline for the Development and Transformation of Education in China.

Tong, Y., Wei, R., \& Xu, H (1999). A Pilot BA Programme: New Prospects for China’s RTVUs in the 21st Century, Paper presented at the 19th World Conference on Open learning and Distance Education, ICDE. June 17-20, Vienna.

Walandouw, H., \& Penrose, T. (1994) Technology and Infrastructure in a Mass Open language learning system. In K. Richards \& P. Roe. (Eds.) Distance Leaning in ELT. London: Modern English Publications in Association with the British Council.

Wei, Y. (1999) To build a lifelong system through modern distance education. Proceedings of the Conference the Open and Distance Education Systems and Models Facing 21st Century's Information and Learning Societies. October, 14-17, 1999. Beijing, China., 57-66.

Wichit, S (1997). Making Distance Education Borderless. Keynot speech delivered at Indira Gandhi National Open University, July 2. New Delhi, India.

Yu, Y. (1999) An analysis of the system mode of china RTVUs. Proceedings of the Conference the Open and Distance Education Systems and Models Facing 21st Century's Information and Learning Societies. October, 14-17, 1999. Beijing, China., 67-81.

Zhang, W., Niu, J., \& Jiang, G. (2002) Web-based Education of Conventional Universities in China: A Case Study. International Review of Research in Open and Distance Learning, 2(2). Retrieved 4th Nov. 2006 from http://www.irrodl.org/index.php/irrodl/article/view/63 